تأثير عدم المحاذاة على الإجهادات المتولدة في أسنان التروس

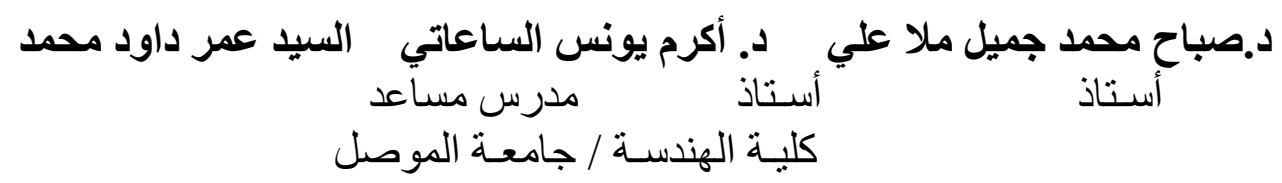

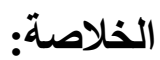

يتمحور هذا البحث حول تحليل الإجهادات المتولدة على سن ترس ناقل للحركة، ودر اسـة

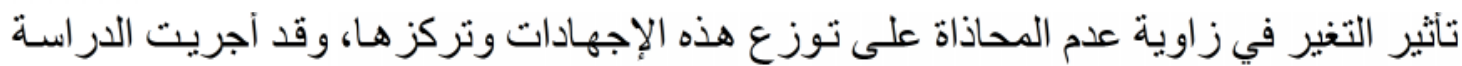

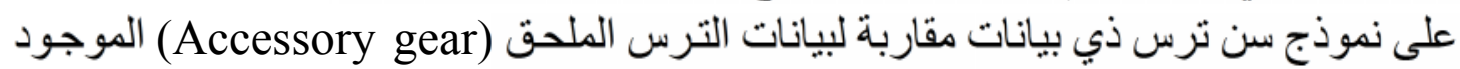

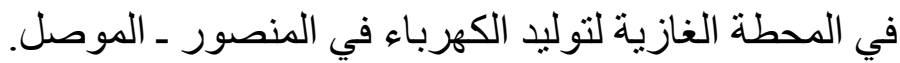

يتضمن هذا البحث تطوير برنامج حاسبة لتقنية العنا وقد تم تحليل نموذج

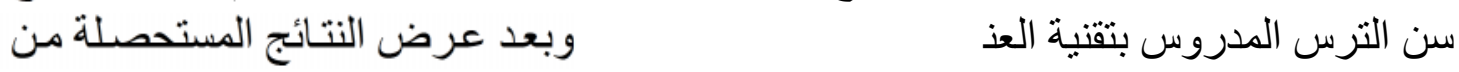

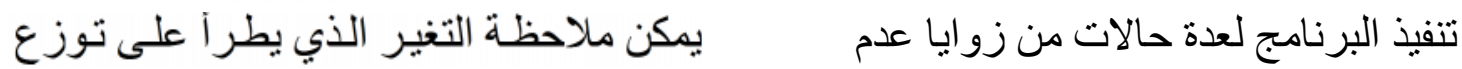

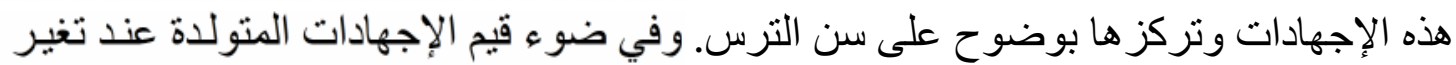

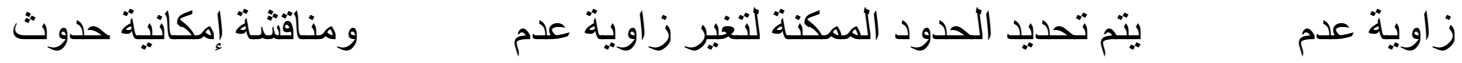
كسر في السن ، ومن ثم اقتر اح نوع المعدن الأنسب للاستخدام من حيث مقاومـة الفتشل .

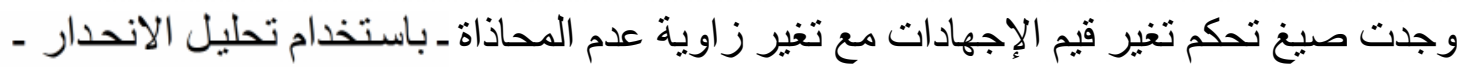

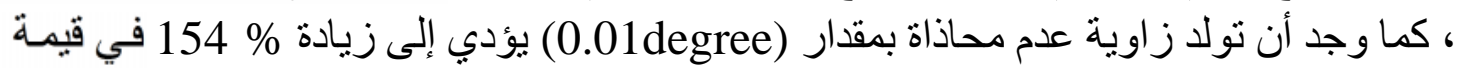

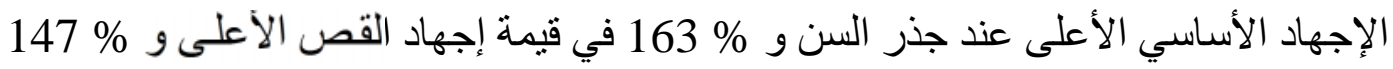
قيمة الإجهاد الأساسي الأدنى في منطقة للتنامس.

\title{
Effect of Misalignment on Gear Teeth Stresses
}

Dr. Sabah M.J.Ali Dr. Akram Y.Al-Sa'ati Mr. Omar D.Mohammed

Professor $\quad$ Professor Assistant

Lecturer

College of Engineering \University of Mosul

\section{Abstract:}

The present research work concentrated on the analysis of stresses generated on transmitting gear tooth, also the effect of misalignment angle on stress distribution and its concentration. This study had been 
done on a gear model similar to accessory gear of Gas Station for electricity generation in Mansour-Mosul.

Computer program using finite element technique had been developed. Gear tooth model had been analyzed using finite element method in three dimensions. The results of execution finite element program for many cases of misalignment angle showed clearly, that the stress distribution and its concentration on tooth changed with misalignment angle. According to the values of generated stresses, the tooth fracture can be predicted, this leads to the selection of more suitable materials to be used for gears. New formulas governing stresses change with change of misalignment angle, had been obtained - using regression analysis -. Also it is found that when angle of misalignment being generated by 0.1 degree, this leads to increase of $154 \%$ in maximum principal stress at root tension side, $163 \%$ in maximum shear stress and $147 \%$ in minimum principal stress at contact region.

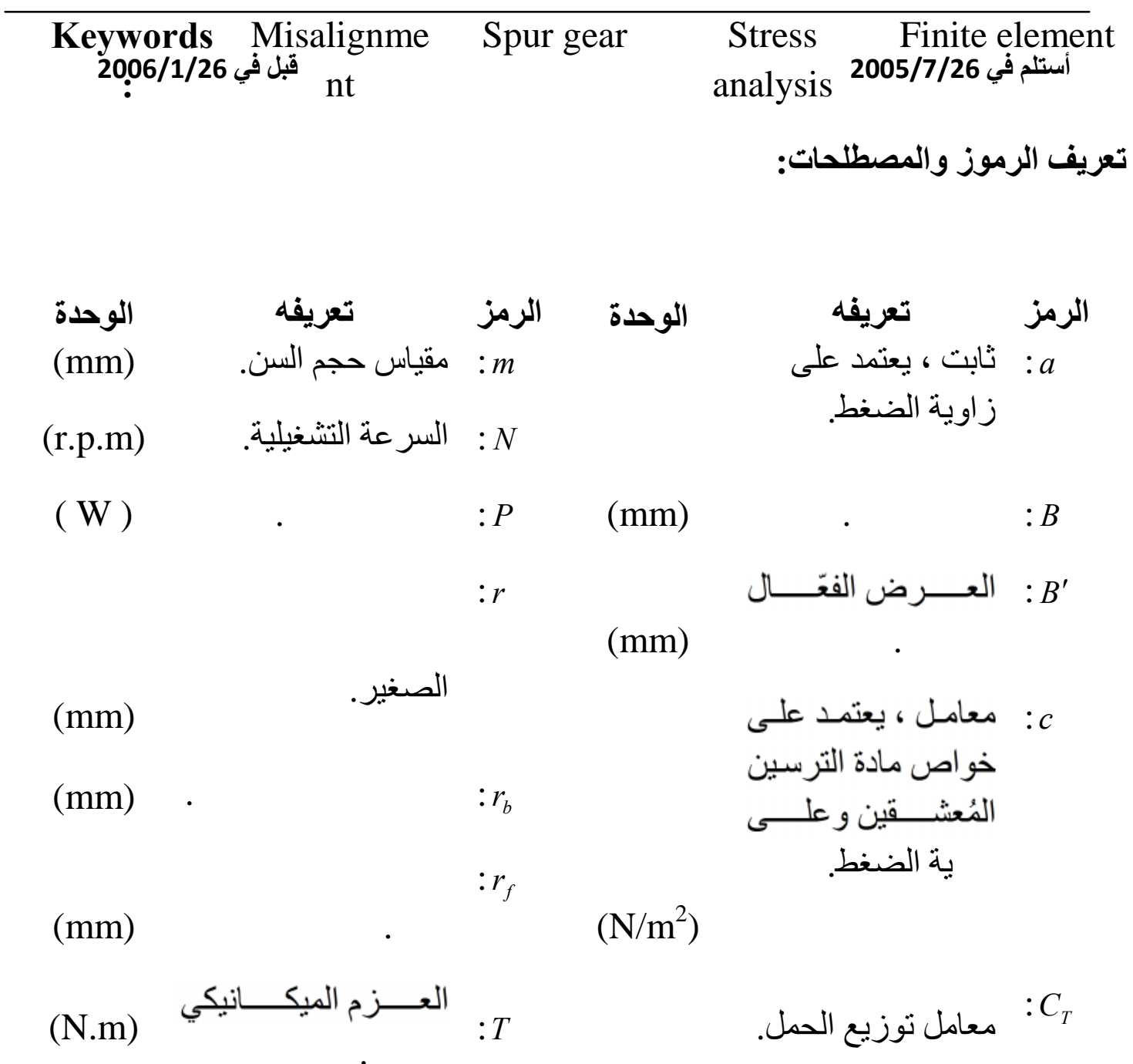




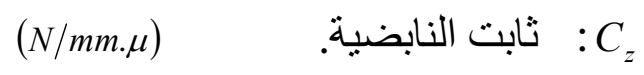

(N)

$(\mathrm{N} / \mathrm{mm}$

)

$$
: u_{m} \quad\left(N / m^{2}\right) \quad \cdot \quad: E
$$

\begin{tabular}{|c|c|c|c|c|}
\hline & أعظم قيمة للحمل & $: u_{\max }$ & (m) & . \\
\hline $\begin{array}{c}(\mathrm{N} / \mathrm{mm} \\
)\end{array}$ & المسلط في توزيع & & & 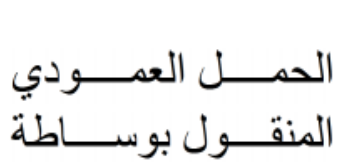 \\
\hline$(\mathrm{m} / \mathrm{sec})$ & 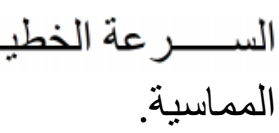 & $: V$ & $(\mathrm{~N})$ & \\
\hline & & $: Z$ & $(\mathrm{~N})$ & مل الديناميكي. \\
\hline
\end{tabular}

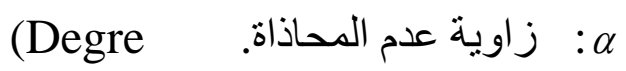

e)

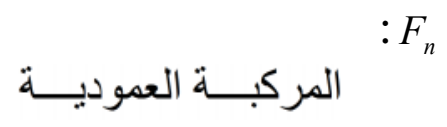

(Radia

n)

(N)

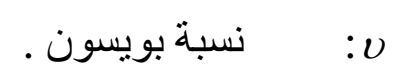

$(\mu)$

: :

(N/mm

2)

$$
\text { : } \sigma_{y}
$$

$$
\text { : : المركبة المماسية }
$$

(Degre

e)

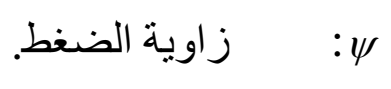

( $\mathrm{rad} / \mathrm{se}$

c)

ف

(mm)

\section{1.المقدمـة:}

تُعد الإجهادات المتولدة في أسنان التروس الناقلة للحركة عـاملا مُحددا بالنسبة لمُصسمي

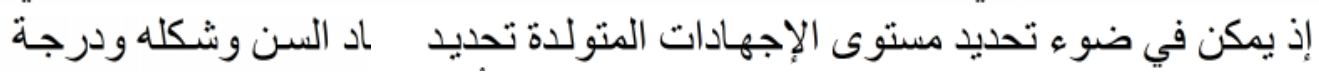
صلادته، فضلا عن سر عة التشغيل والحمل المنقول و غير ها من أمور التصميم الو اجب التبل تحديدها. وتكمن أهمية دراسة تحليل الإجهادات في تحديد آمـاكن تركز الإجهادات المتوقع آن بيداً عندها 
أجريت بحوث ودر اسـات عديدة اعتمدت أسـاليب مختلفة في تحليل الإجهادات المتولدة

فصيغة لويس (Lewis equation)

(Beam)

أجريت در اسات عديدة باستخدام تقنية المرونـة الضوئية (Photoelasticity technique)

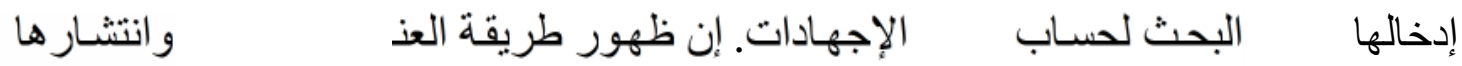

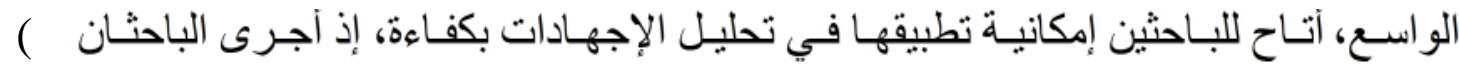
الإع L.Wilcox and W.Coleman)

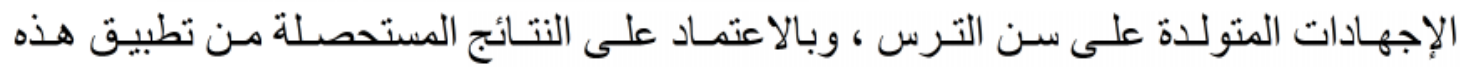

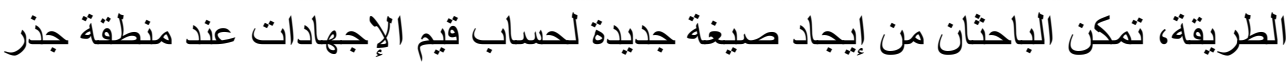

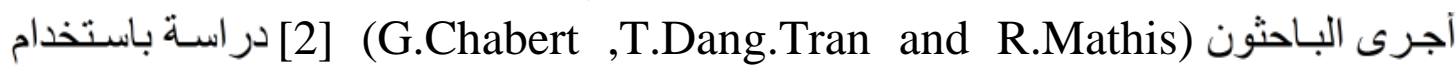

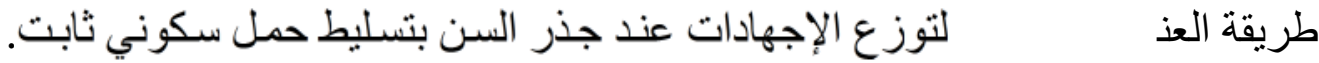

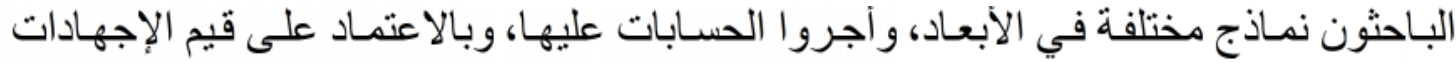

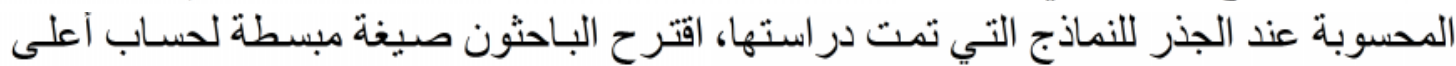

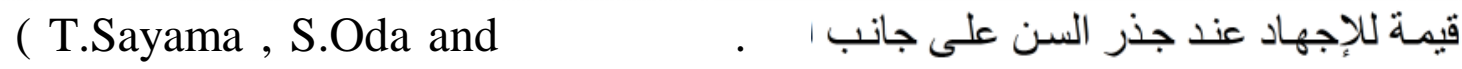

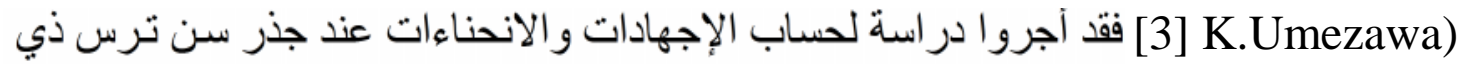

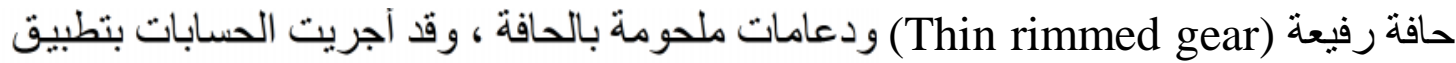

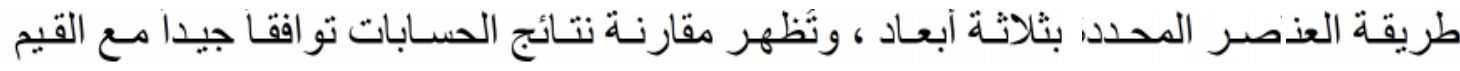

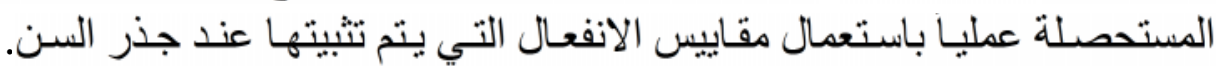

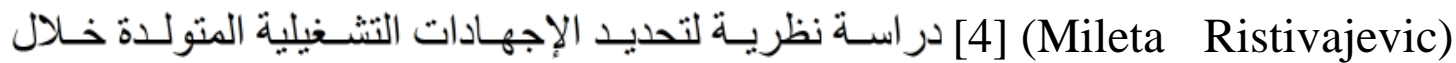

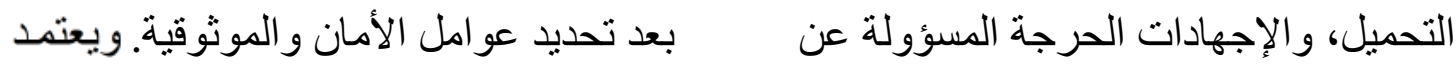

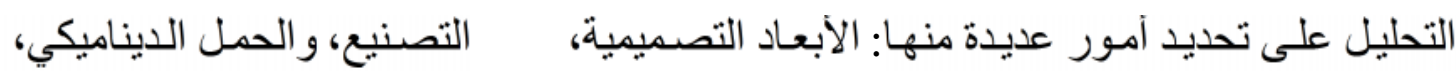

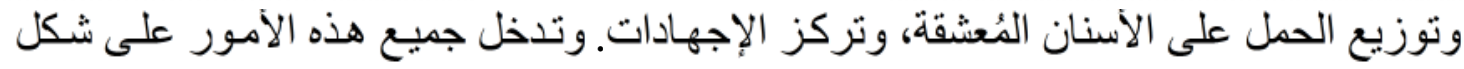

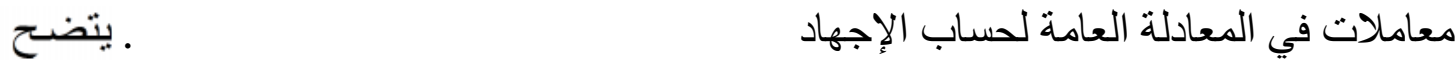

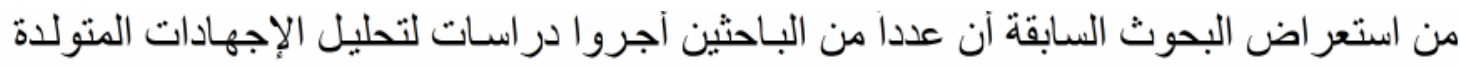

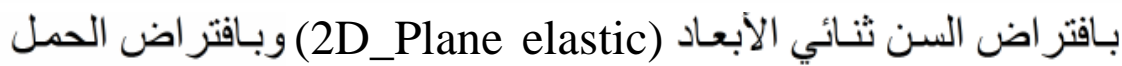

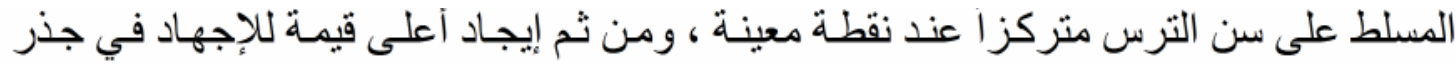

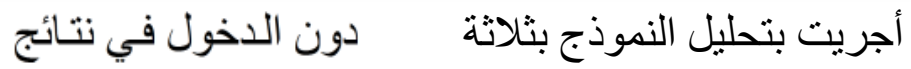

تغير تسليط الحمل، من تغير في توزيع الإجهادات وتركز ها مع تغير زاوية عدم المحاذاة.

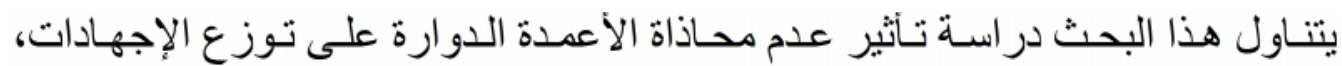

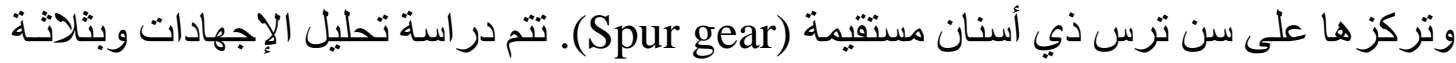

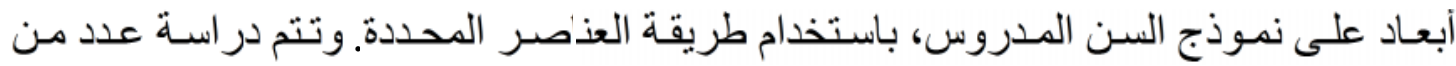

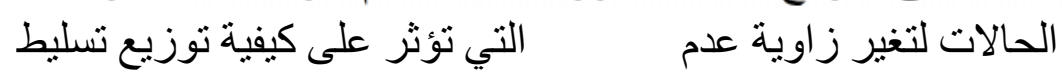

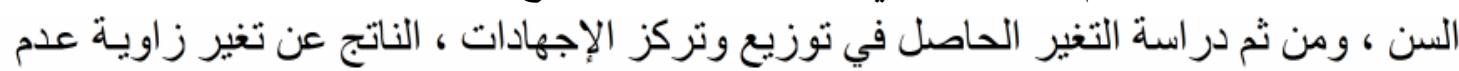




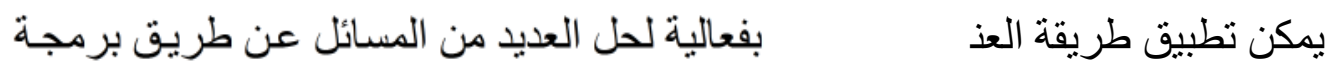

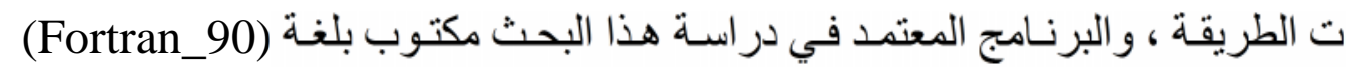

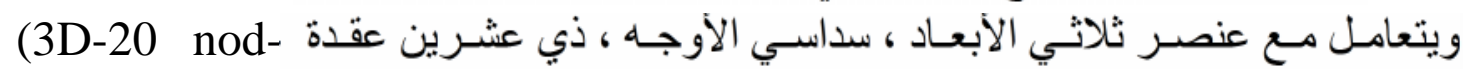

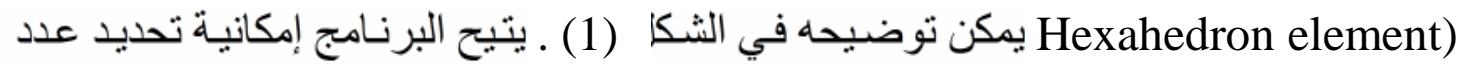

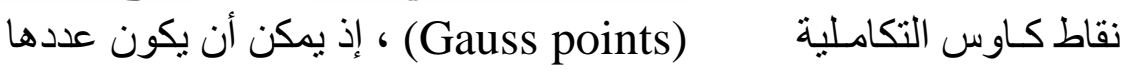

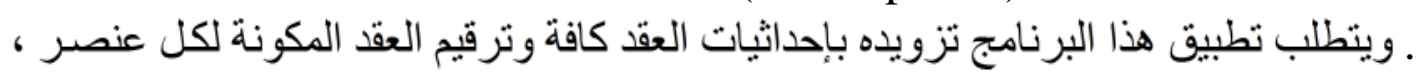

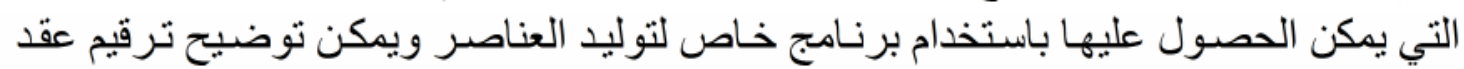

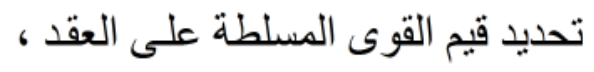

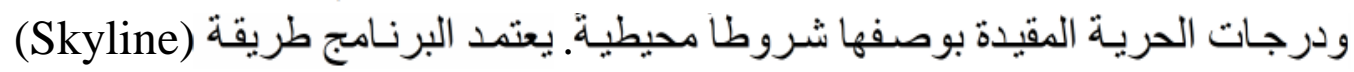
. و و عند تنفيذ البرنامج

لخزن مصفوفة الجساءة ، كما يعتمد طريقة (Cholesky)

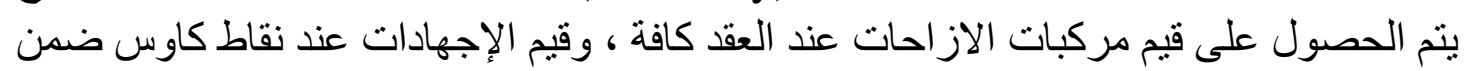

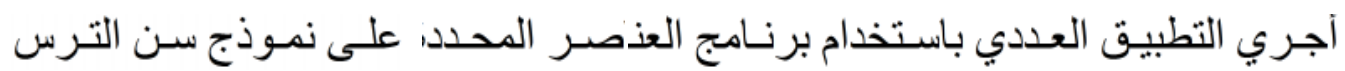

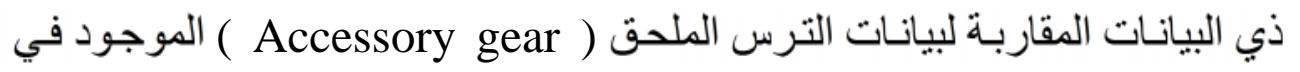

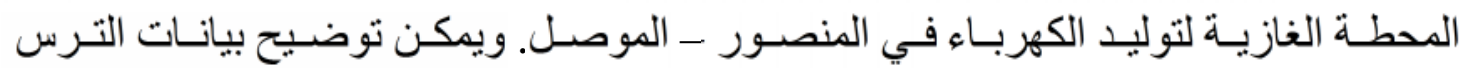

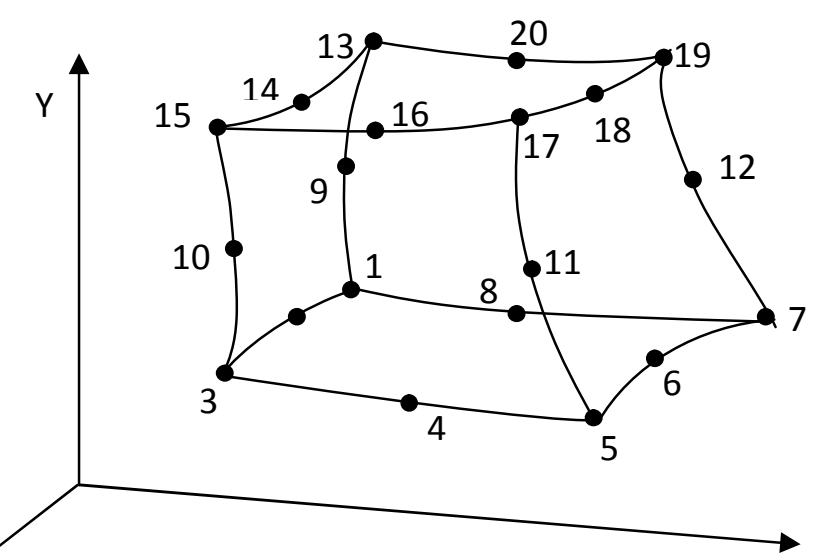




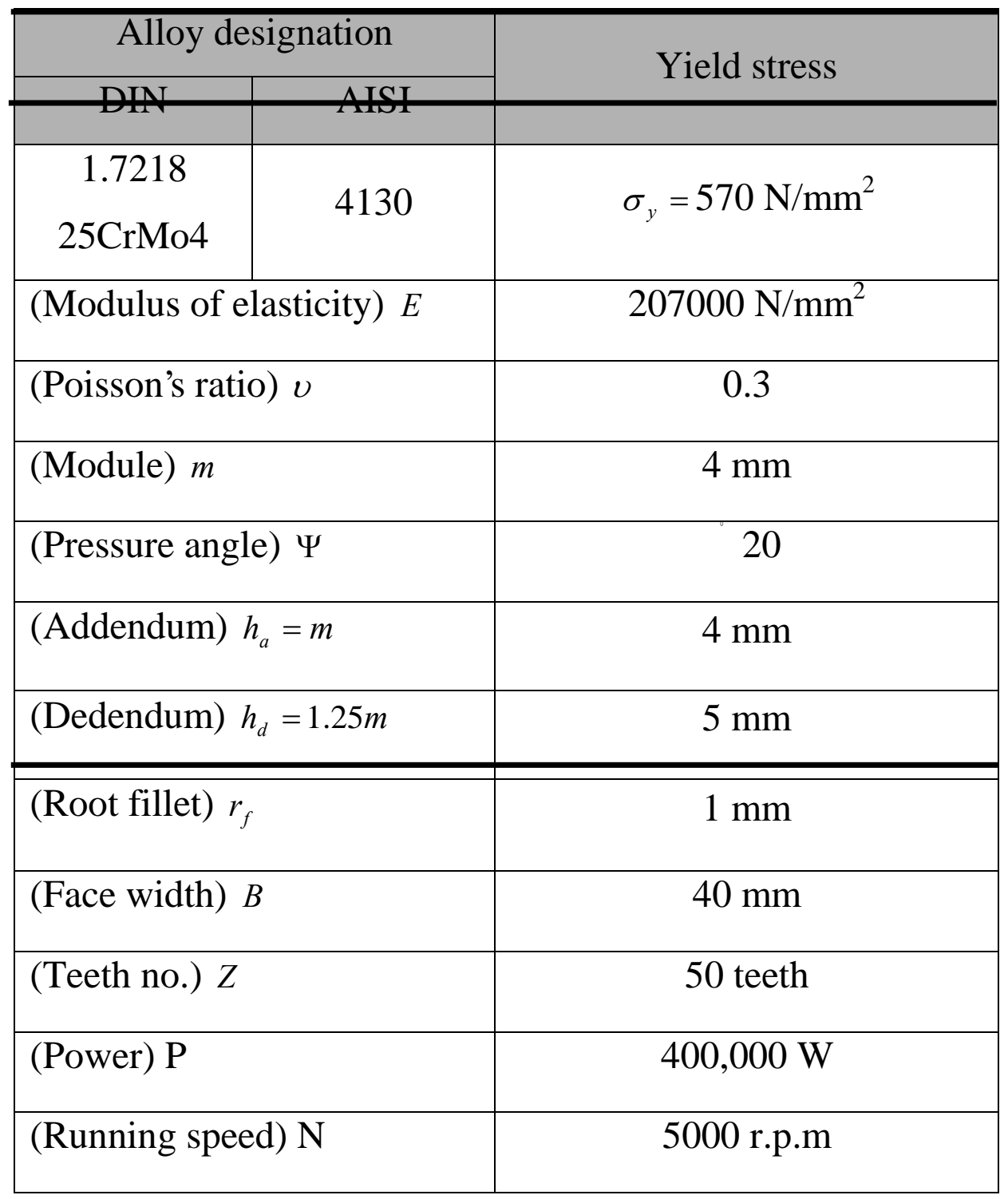


(1) (1) (1) بيانات الترس المدروس.

1.3. تمثيل النموذج بطريقة العناصر المحددة:

عنصر ا ثلاثي الأبعاد ،

سن الترس

سداسي الأوجـه ، ذي عشرين عقدة ، ويوضح الثكل(2) تقسيمات النموذج مع تثبيت الإحداثيات

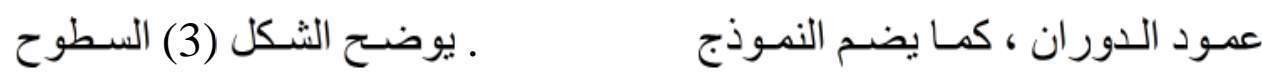

الجانبية (C,B ,A) للنموذج ، المثبتة بحيث تكون درجات الحريـة للنقاط الو اقعة عليها مقيدة

.(z, y, x)
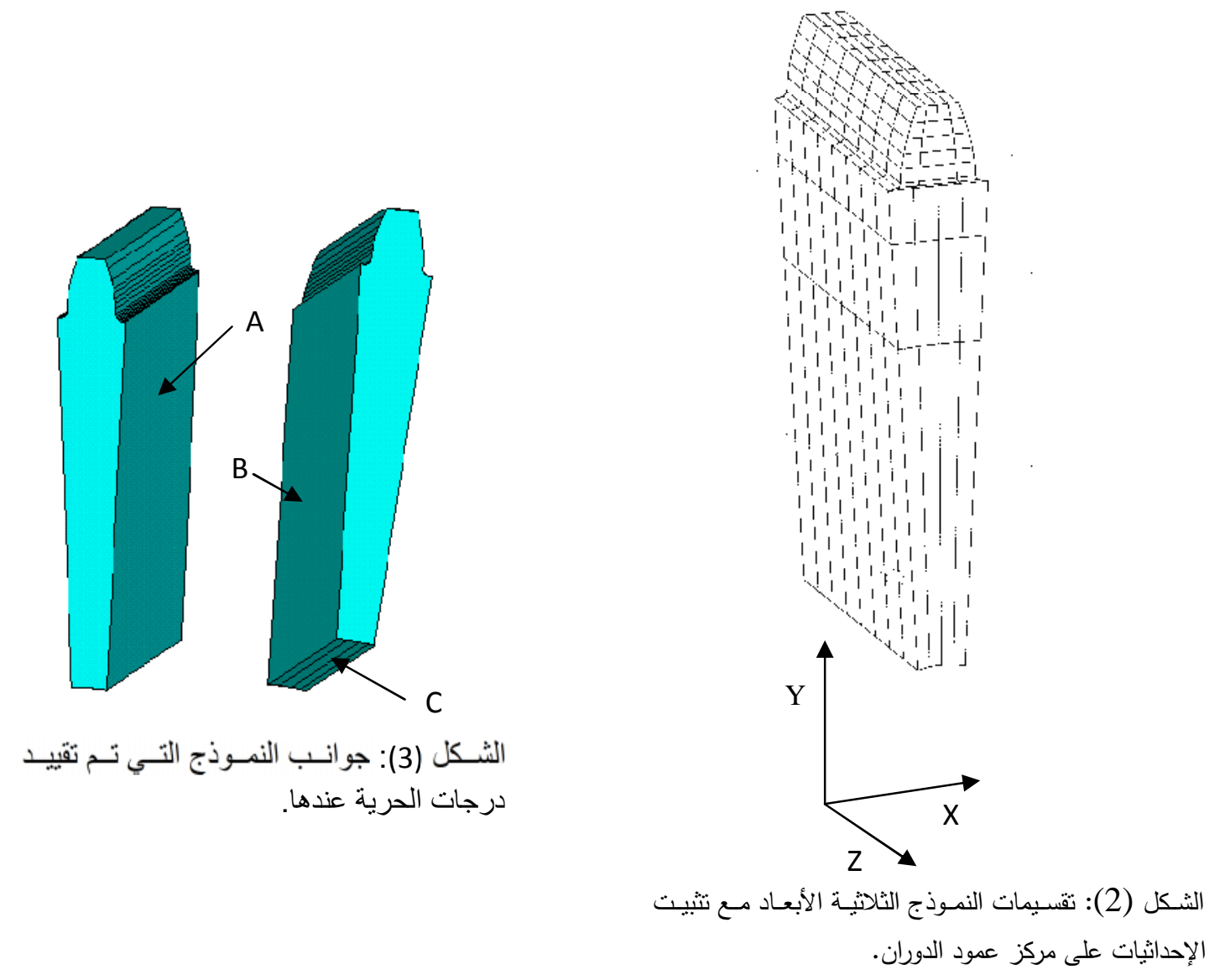


\section{4.حساب الحمل المسلط:}

يتوجب حساب الحمل المسلط على سن الترس الترس

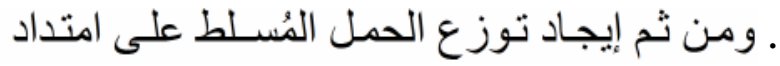

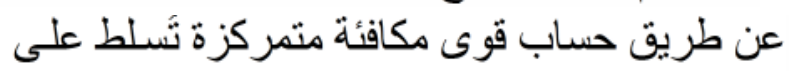

لغرض تطبيق طريقة العذ

بعد إيجاد الحمل الديناميكي

عرض السن عند تغير زاوية عدم العين

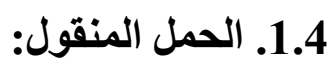

- $T=P / \omega$

$\omega=2 \pi N / 60$

$$
\text { وبتعويض القيم من الجدول (1) يمكن حساب T }
$$

$$
T=763.943 N \cdot m
$$

- $F=T / r_{b}$

$$
\begin{array}{r}
r_{b}=r \cdot \cos (\Psi) \\
r=m \cdot z / 2
\end{array}
$$

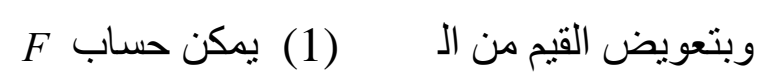

$$
F=8129.74 N
$$

$$
\text { في هذا البحث تكون نسبة التلامس (C.R=1.7) }
$$

التتلامس سيكون بزوجين مقسما بالتسـاوي

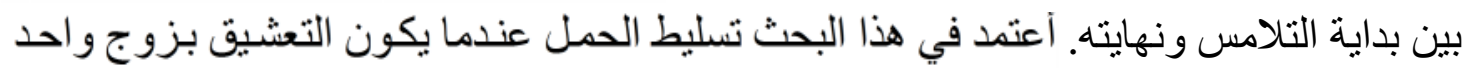

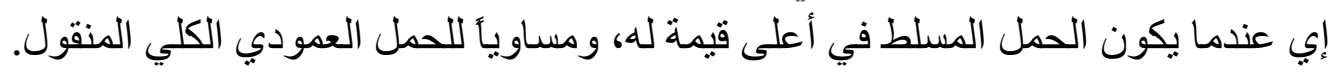
تتولا أعلى إجهادات عند جذر السن.

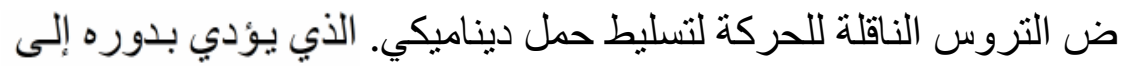

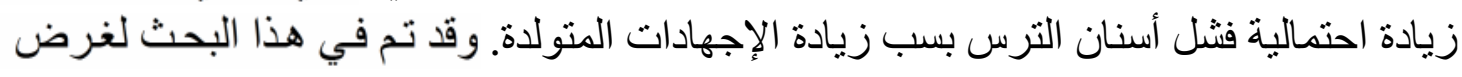

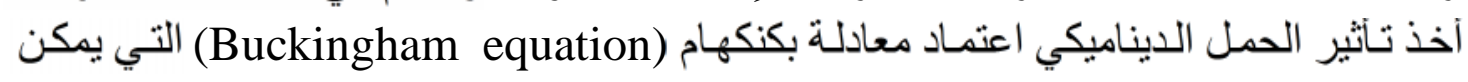

$$
\text { وصفها على النحو الآتي [6]: }
$$




$$
F_{d y n}=F_{t}+\frac{21 V\left(B c e+F_{t}\right)}{21 V+\sqrt{B c e+F_{t}}}
$$

$$
\begin{aligned}
& e=2 \times 10^{-6} m \text { يمكن إيجاد (e) ، بعد الرجوع إلى جداول سماحية الخطأ[6] ، لنكون قيمته } \\
c= & \frac{a\left(E_{p} E_{g}\right)}{\left(E_{p}+E_{g}\right)}
\end{aligned}
$$

$a\left(\Psi=20^{\circ}\right)=0.111 \quad, \quad E_{p}=E_{g}=207 \times 10^{9} \mathrm{~N} / \mathrm{m}^{2} \quad$ (For pinion and gear)

$\therefore F_{d y n}=15527.377 \mathrm{~N}$

2.4. توزع الحمل على امتداد عرض السن:

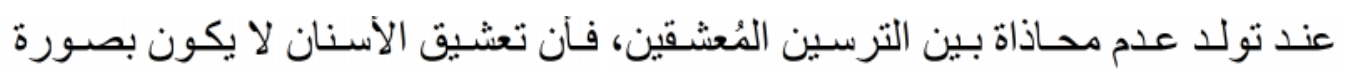

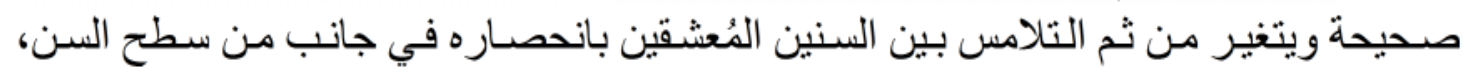

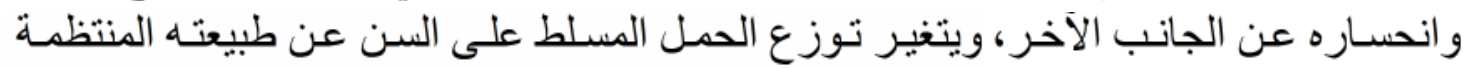

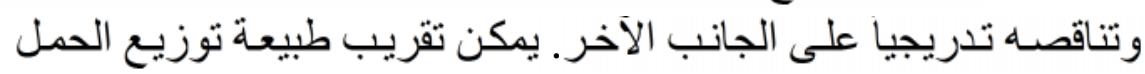

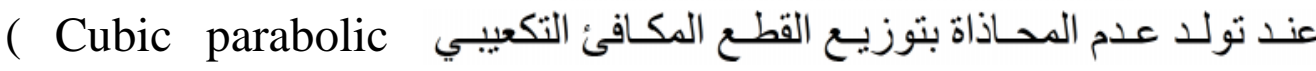

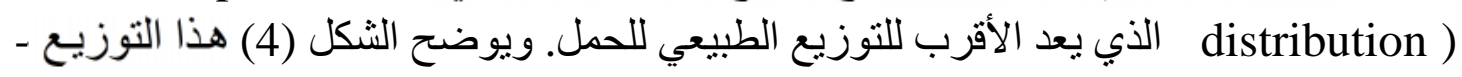
يمكن وصفه بالمعادلة الآتية: [7]:

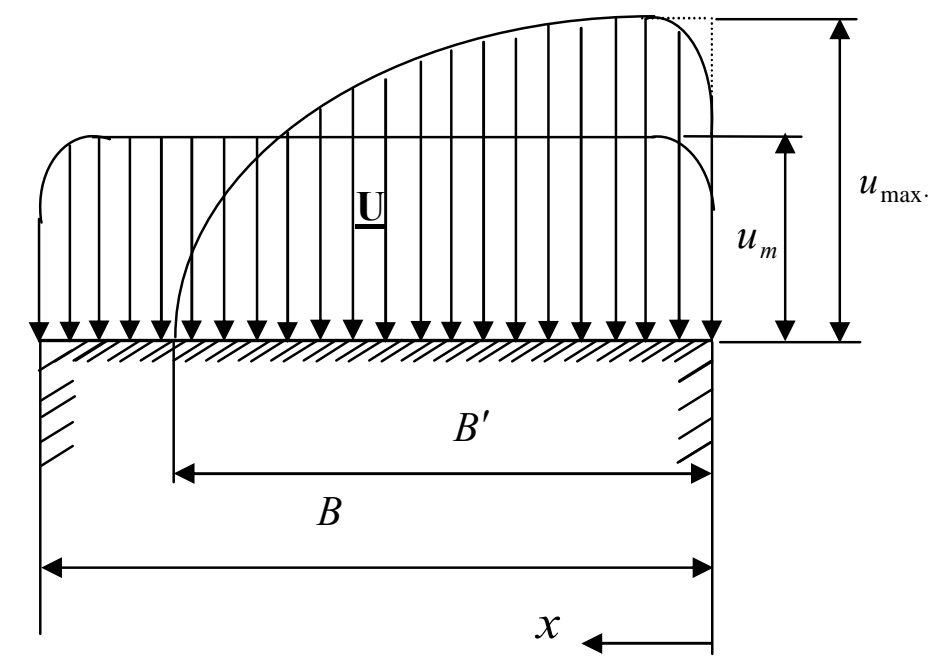

الثكل (4): توزع الحمل في حالتي المحاذاة التامة وعدم المحاذاة. 


$$
u(x)=u_{\max } \cdot\left[1-\left(x / B^{\prime}\right)^{3}\right]
$$

ويمكن تعريف الحمل المماسي المسلط على امتداد عرض السن على النحو الآتي [7]:

$$
U=u_{m} \cdot B=\int_{0}^{B^{\prime}} u(x) \cdot d x=\frac{3}{4} B^{\prime} u_{\max }
$$

$$
\begin{aligned}
& u_{m}=\frac{U}{B} \ldots \ldots \ldots \ldots \\
& u_{\max }=\frac{4 U}{3 B^{\prime}} \ldots \ldots \ldots . .
\end{aligned}
$$

$$
\text { أيضـاً [7]: }
$$

$$
\text { ) } u_{\max .} \text { (قد وجد عمليًا أنه يمكن حساب }
$$

$$
u_{\max }=C_{z} \cdot f_{R W} \frac{B^{\prime}}{B}
$$

$$
\text { ويمكن تعريف }
$$

$$
C_{z}=\frac{K}{B} \times 10^{-3}
$$

$$
f_{R W} \text { كما يمكن تعريف }
$$

$$
f_{R W}=10^{3} \cdot \alpha \cdot B
$$

يمكن التوصل إلى قيمة العرض الفعال ) B ( من المعادلتين (7) (8). 


$$
B^{\prime}=\sqrt{\frac{4 U \text { B }}{3 f_{R W} \cdot C_{z}}}
$$

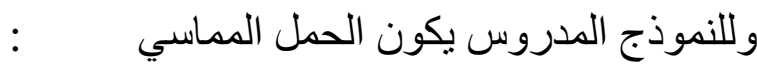

$$
U=F_{d y n}=15527.377 \mathrm{~N}
$$

ويمكن تعريف معامل توزيع الحمل ( Load distribution factor) ليكون:

$$
C_{T}=\frac{u_{\max }}{u_{m}}
$$

في هذا البحث تم حسـاب توزيع الحمل على سـن الترس لحـالات عدم المحساذاة التي اختيرت للار اسة ويمكن توضيحها في الجدول الآتي:

\begin{tabular}{|c|c|c|}
\hline $\begin{array}{c}\text { Cas } \\
\mathrm{e}\end{array}$ & $\alpha($ radian $)$ & $\alpha(\operatorname{deg}$ ree $)$ \\
\hline 1 & 0.000 & 0.000 \\
\hline 2 & 0.000512 & 0.02933 \\
\hline 3 & 0.000681 & 0.03901 \\
\hline 4 & 0.000952 & 0.05454 \\
\hline 5 & 0.00180 & 0.10313 \\
\hline 6 & 0.00320 & 0.18334 \\
\hline
\end{tabular}

$$
\text { (2): زوايا عدم المحاذاة التي اختيرت لللدراسة }
$$

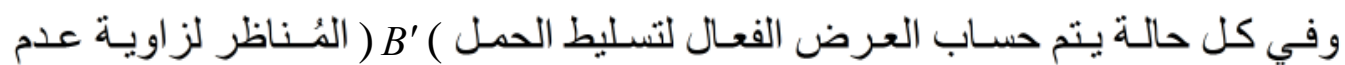
المحساذاة في تلك الحالـة، يتم بعد ذلك حسـاب ) (، ومـن ثم يتم إيجـاد قيم القوى المكافئة المتمركزة على العقد، التي تمثنل الحمل الحقيقي الموزع لتلك الدلّة، ويتم ذللك بإجر اء تكامل 
$F=\int_{x_{1}}^{x_{2}} u_{\max } \cdot\left[1-\left(\frac{x}{B^{\prime}}\right)^{3}\right] \cdot d x$

ويمكن توضيح نتائج الحسابات لحالات عدم المحاذاة التي تمت در استها على النحو

\begin{tabular}{|c|c|c|c|c|c|}
\hline Case & $\begin{array}{c}\alpha \\
\text { (Radian) }\end{array}$ & $f_{R W}(\mu)$ & $B^{\prime}(\mathrm{mm})$ & $u_{\max .}(N)$ & $C_{T}$ \\
\hline 1 & 0.000000 & 0.00 & $B=40$ & $u_{m}$ & 1.0 \\
\hline 2 & 0.000512 & 20.48 & 37.5 & 552.08 & 1.42 \\
\hline 3 & 0.000681 & 27.25 & 32.5 & 637.02 & 1.64 \\
\hline 4 & 0.000952 & 38.08 & 27.5 & 752.84 & 1.94 \\
\hline 5 & 0.001800 & 72.0 & 20.0 & 1035.15 & 2.66 \\
\hline 6 & 0.003200 & 128.0 & 15.0 & 1380.21 & 3.55 \\
\hline
\end{tabular}

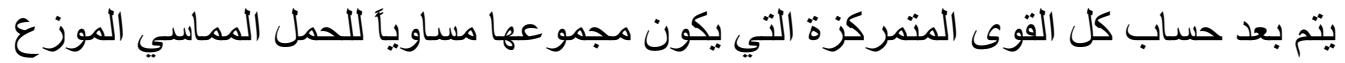

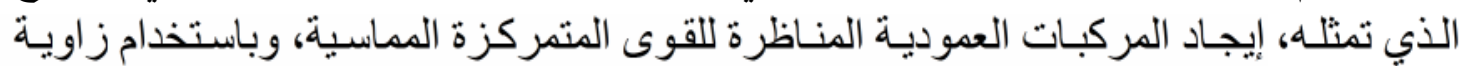
:[8] $) \Psi($

$$
F_{n}=F_{t} \tan (\Psi)
$$

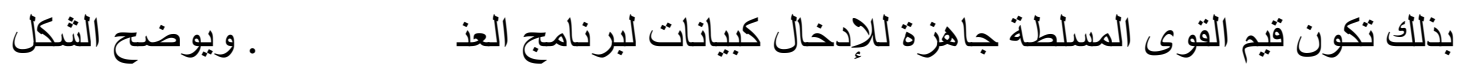

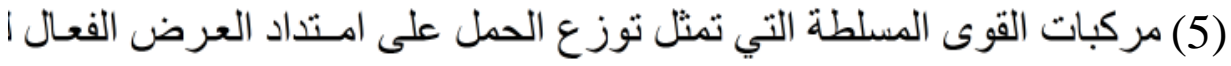
لقيمة زاويـة عدم المحاذاة. 


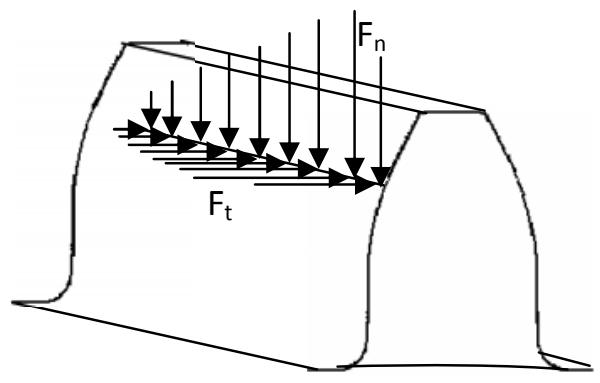

الثكل (5): مركبات القوى المكافئة

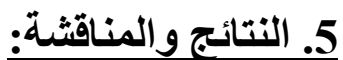

يمكن تقديم النتائج المستحصلة من هذا العمل ومناقشتها بتناول الرسومات و المنحنيات

(f-a 6) 1. رسومات المناسيب لتوزع الإجهادات على مقطع أققي في السن:

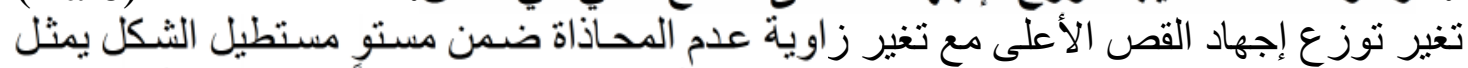

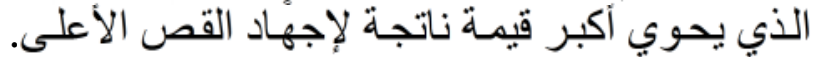

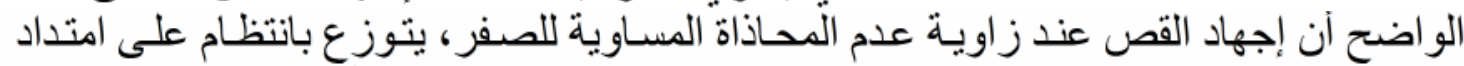

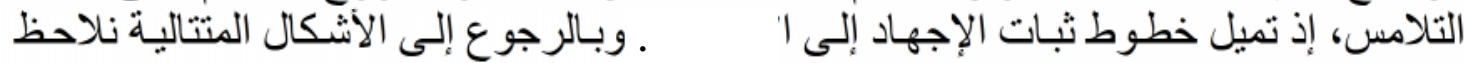

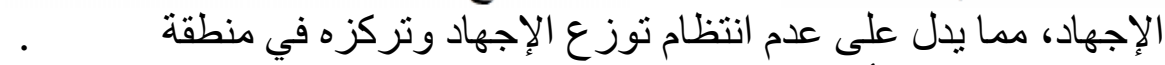
وبذلك تنز ايد أكبر قيمة لإجهاد القص الأعلى مع تز ايد زاوية عدم المحاذاة. 


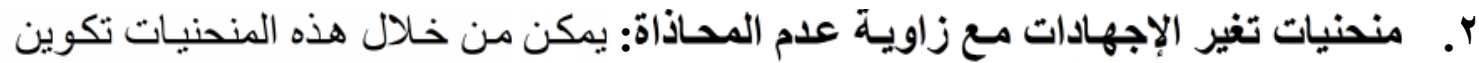

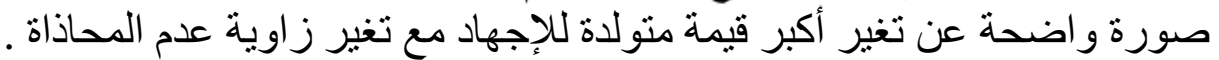

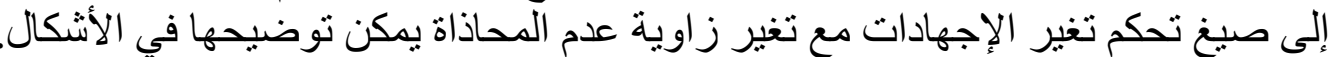

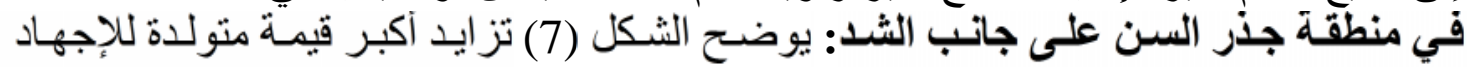

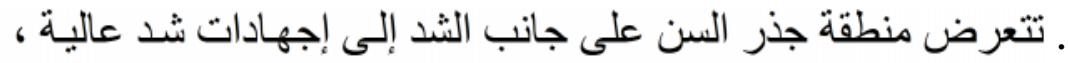

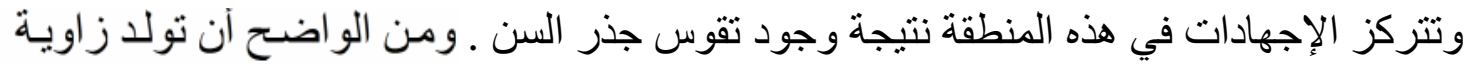
(0.1 degree)

تركز الإجهاد (Kc=2.47) . يمكن توقع حدوث فثل في جذر السن بعد تجاوز إجهاد الثدا

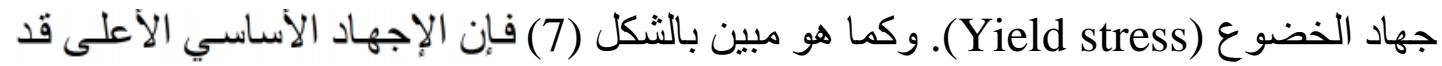

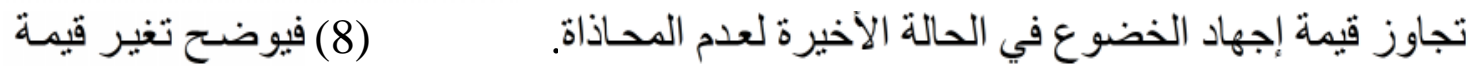

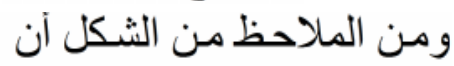

الإجهاد المكافئ المحسوب حسب معيار (Von mises) القيم تنز ايد إلا أنها لاتصل قيمة إجهاد الخضوع. في منطقة التلامس: يوضح الثكل (9 ) تز ايد أكبر قيمة متولدة لإجهاد القص الأعلى في السن.

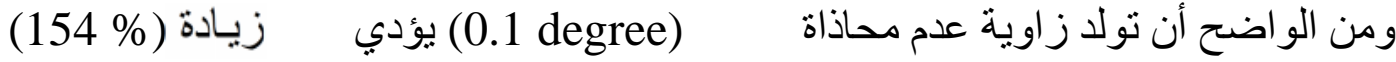

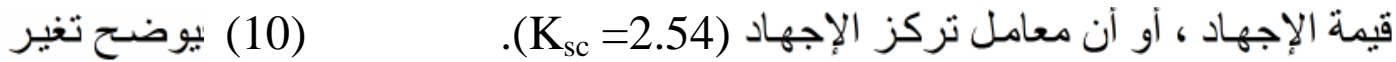

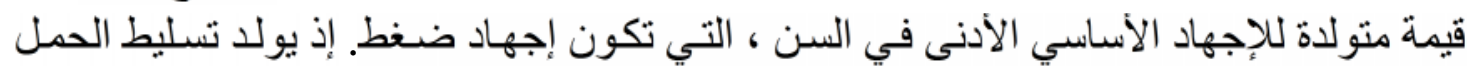

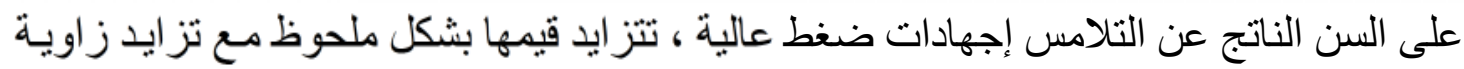

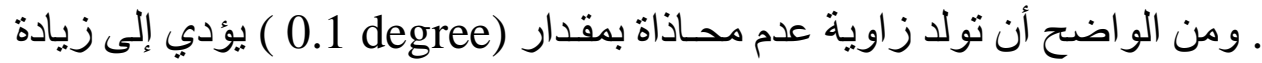

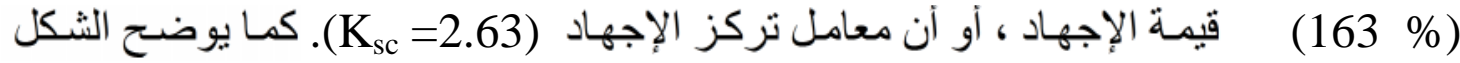

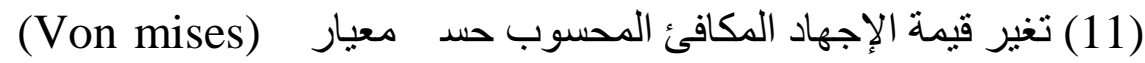

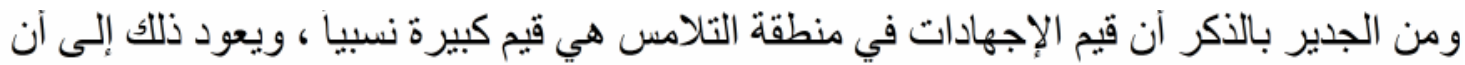

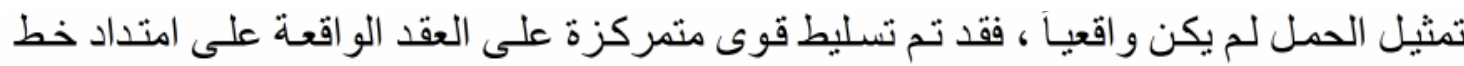

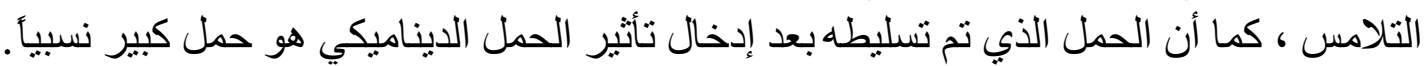

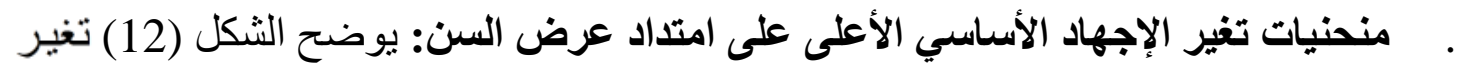

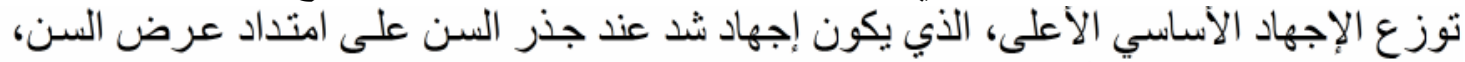

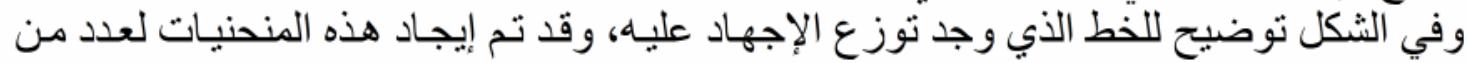

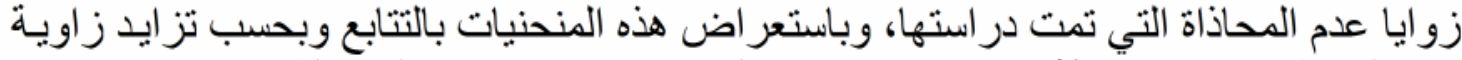

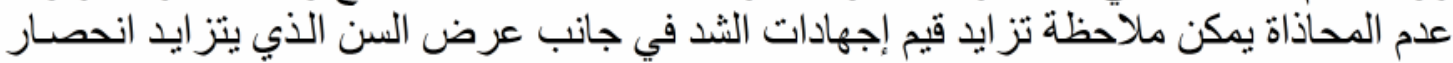

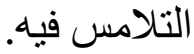

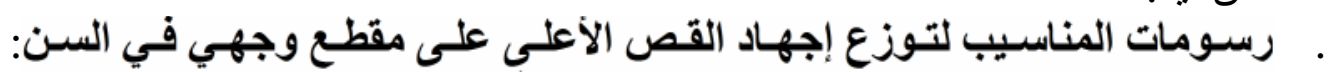

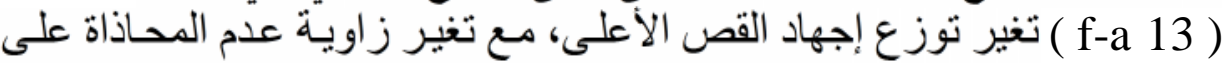

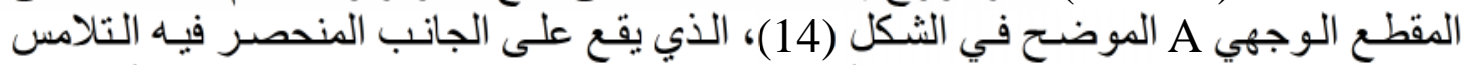

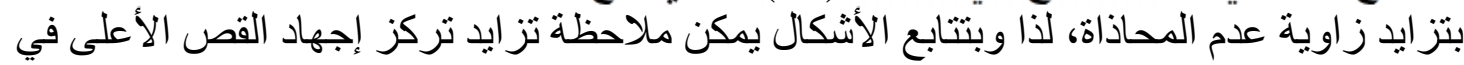

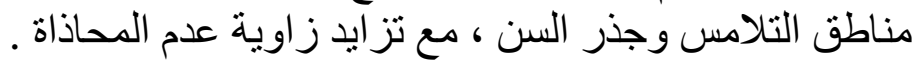
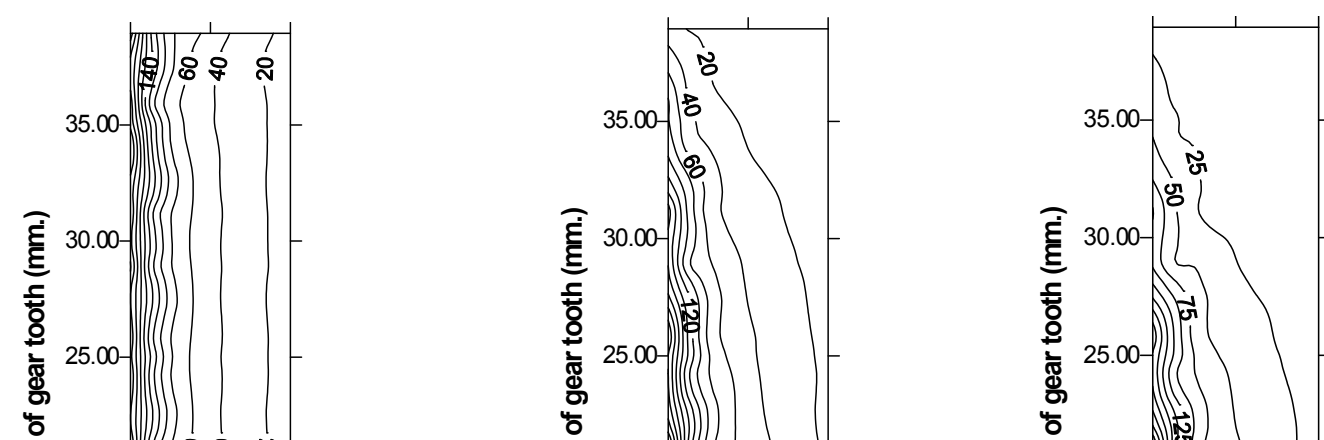



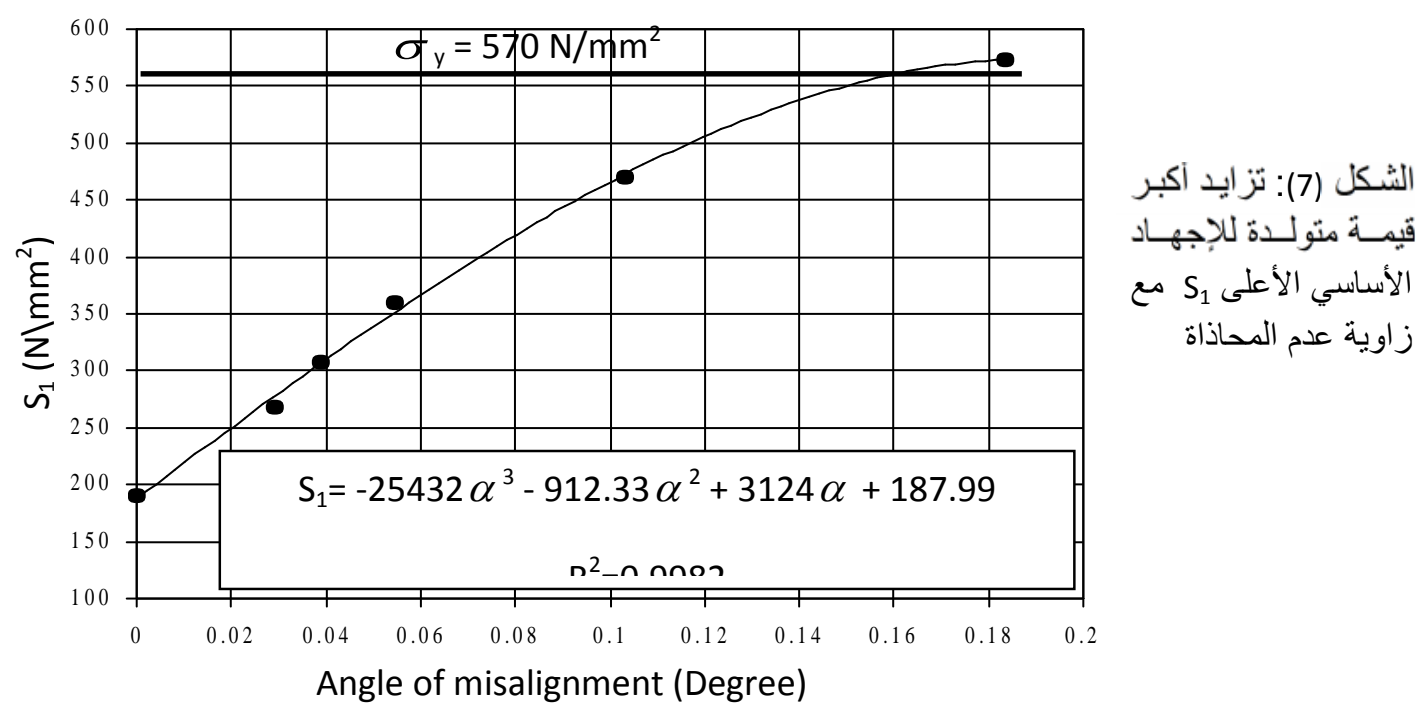




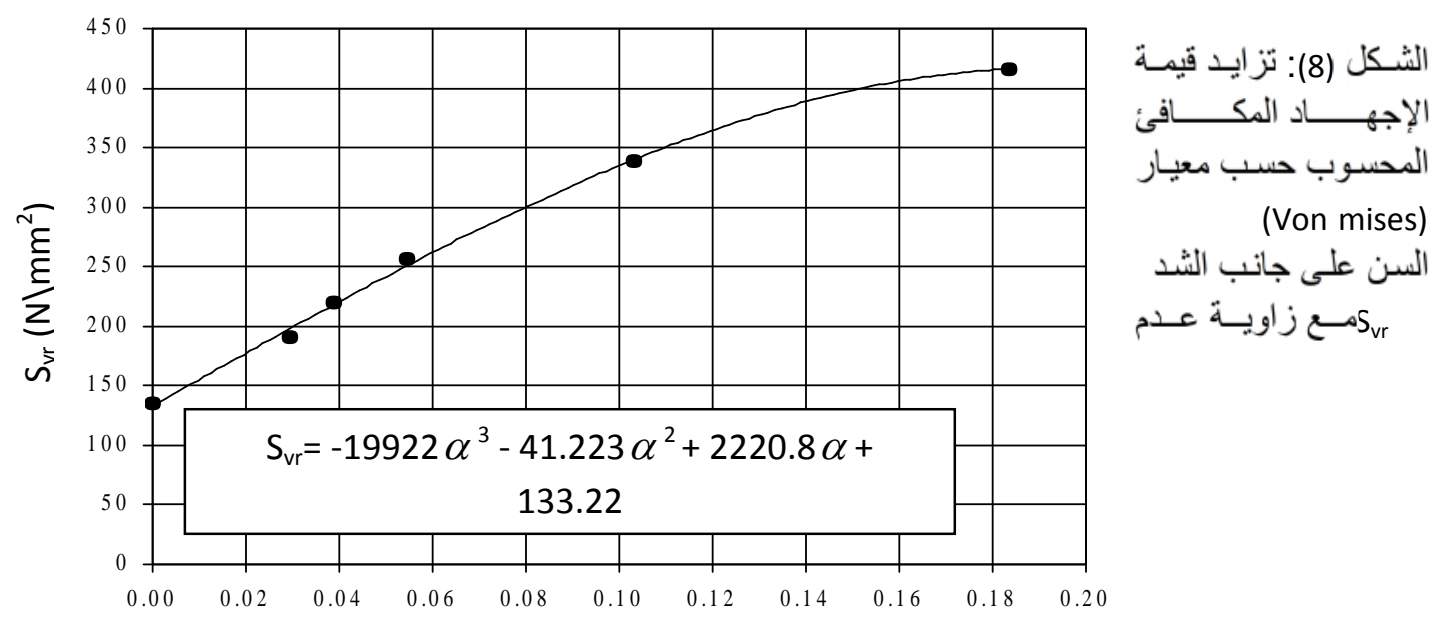

Angle of misalignment (Degree) 


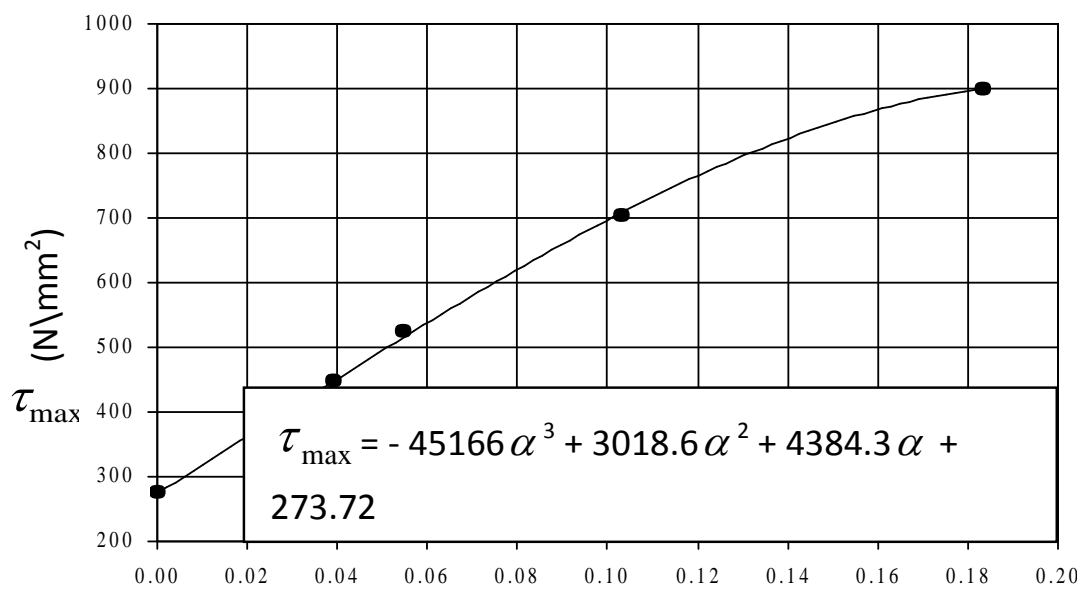

الثــل (9): تز ايــ أكبر

قيمسة منو لــدة لإجهــاد

$\tau_{\max }$

زاوية عدم المحاذاة

Angle of misalignment (Degree)

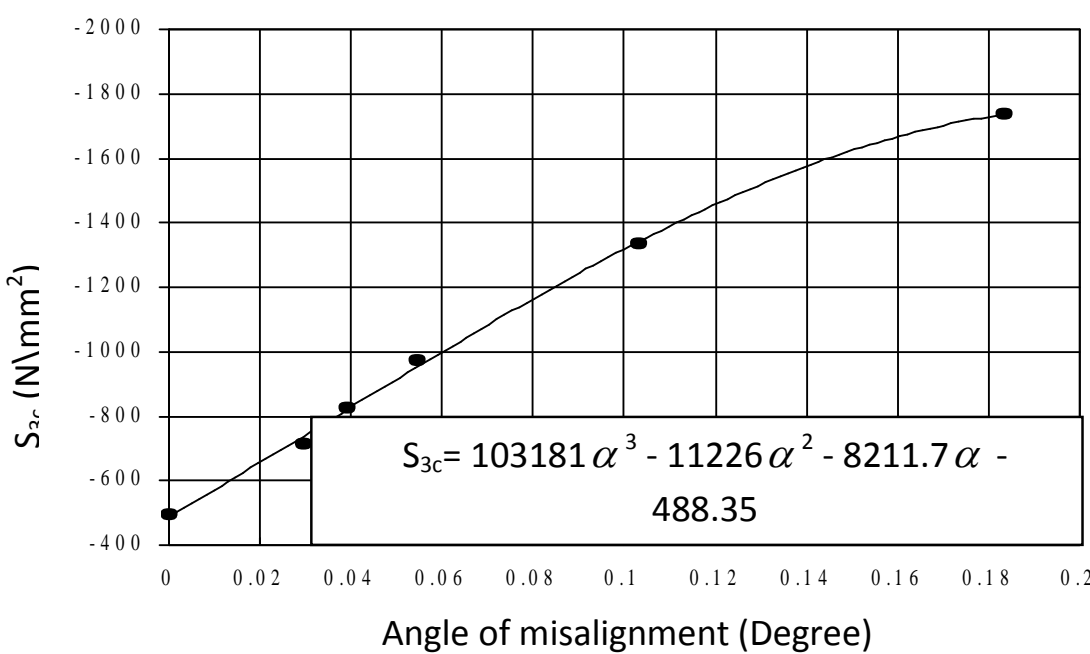

قيمسة متولــدة للإجهــاد

$\mathrm{S}_{3 \mathrm{c}}$

زاوية عدم المحاذاة

Angle of misalignment (Degree) 

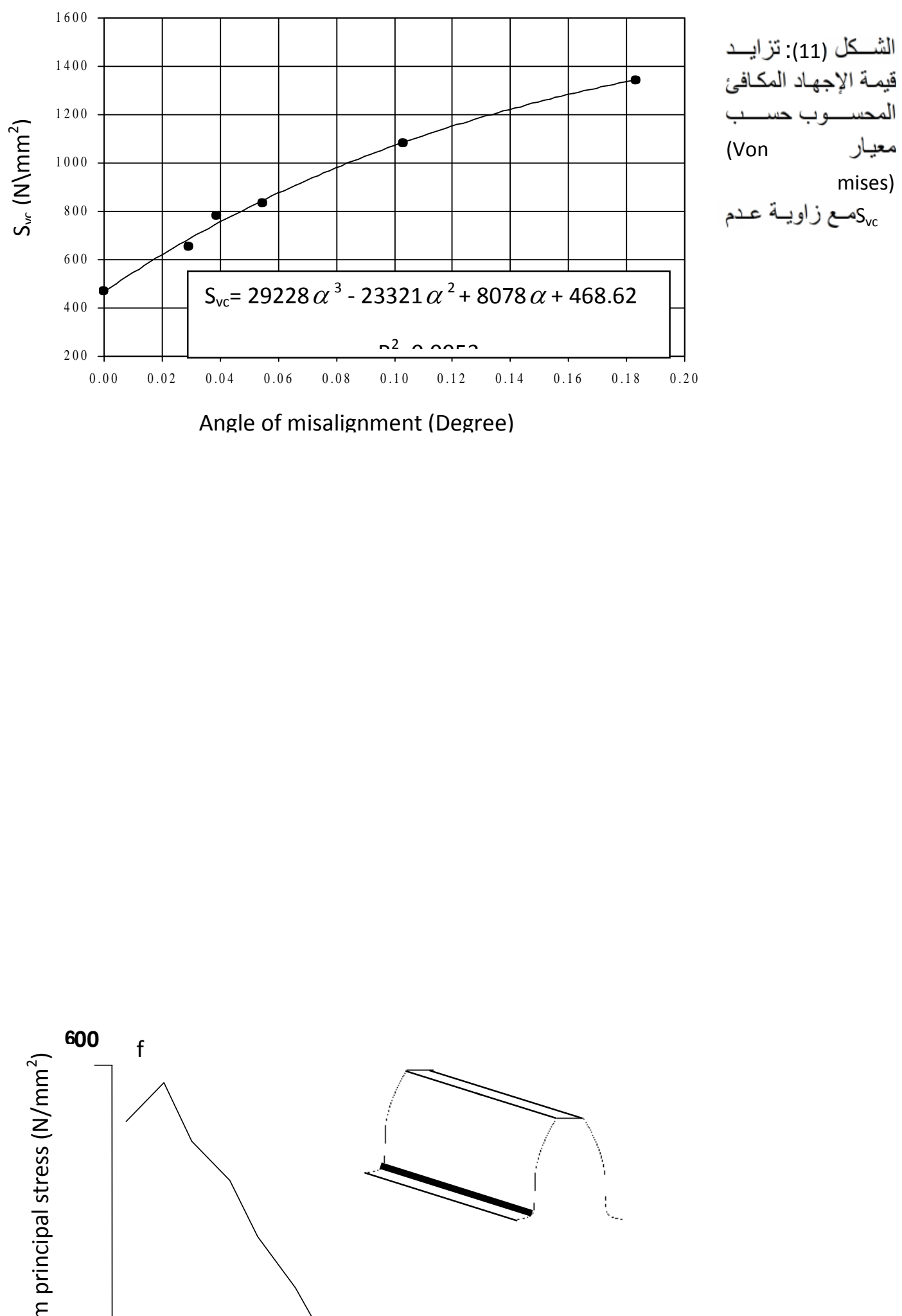


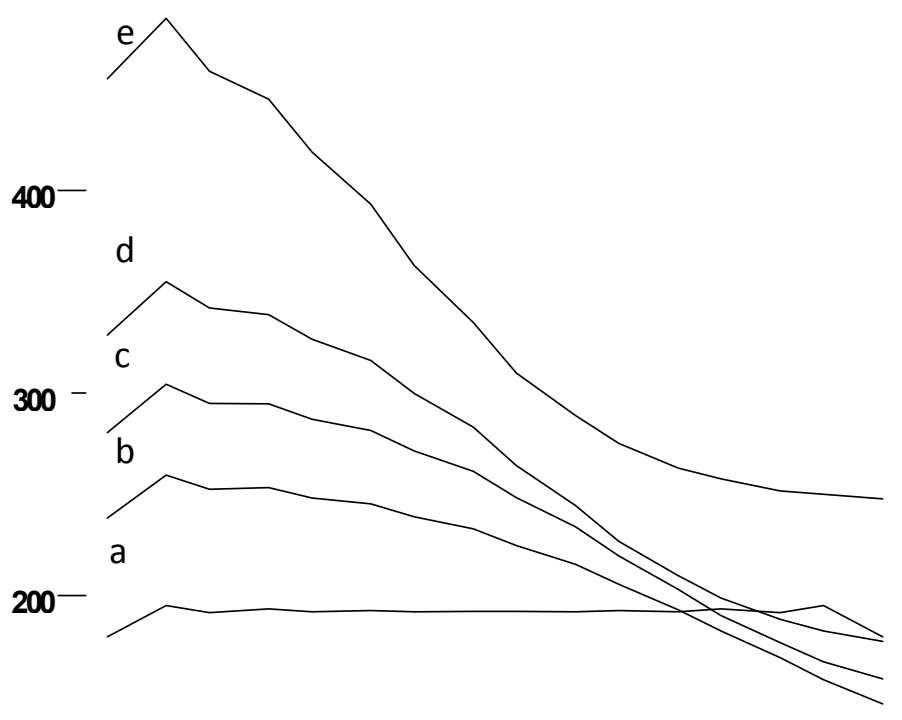

(12): تخير تـوز ع

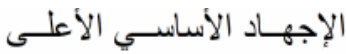

عند جذر السن على جانب

الثد مع زاوية عدم المحاذاة

100

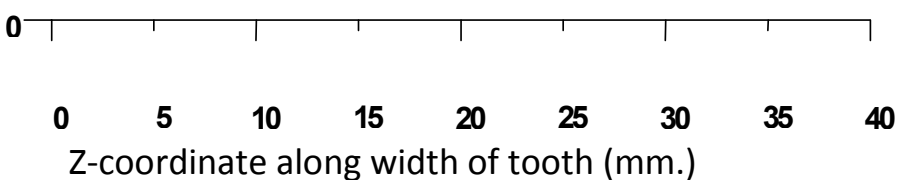

Z-coordinate along width of tooth $(\mathrm{mm}$.)

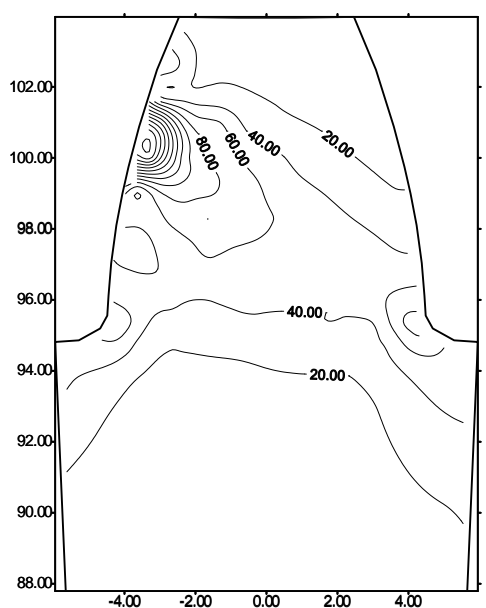

a: $\alpha=0.000$ degree

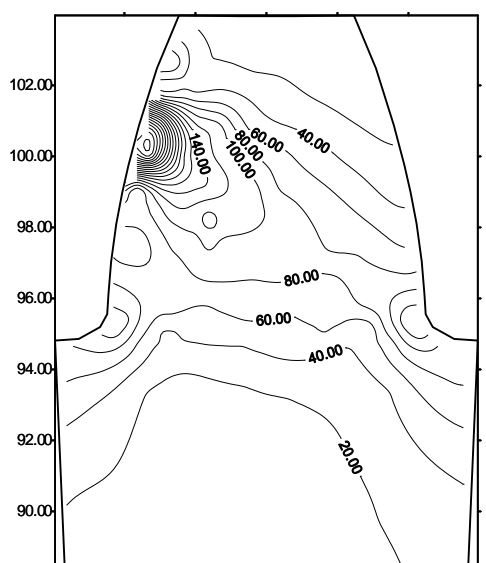

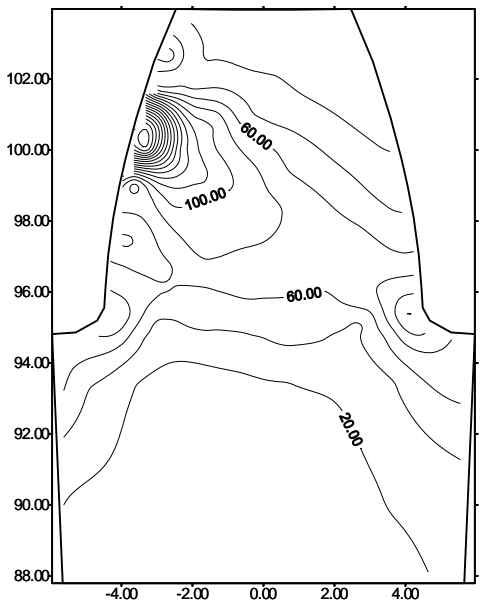

b: $\alpha=0.02933$ degree

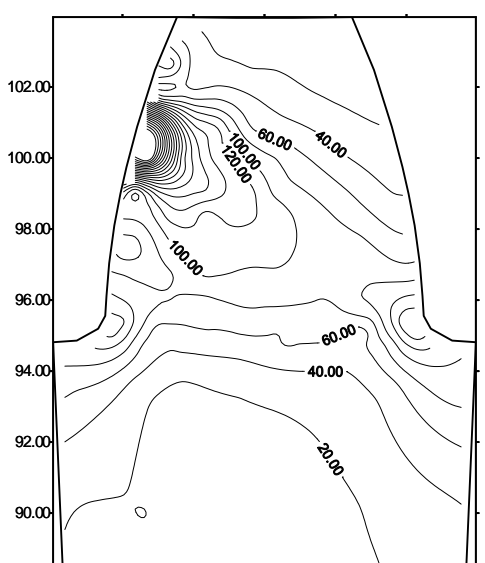





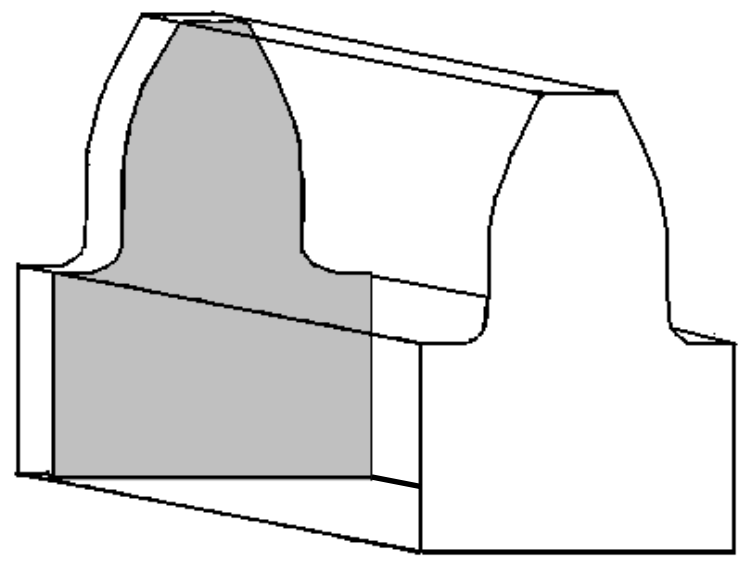

(14): المقطع الوجهي (Z-coordinate =6.05662 mm.) A 


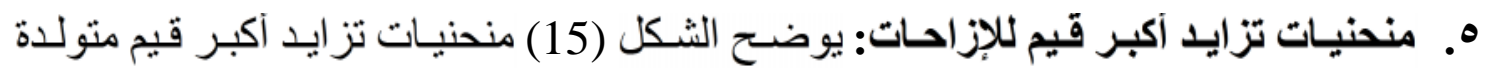

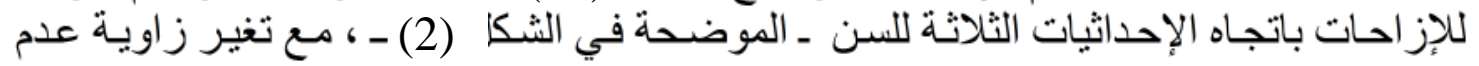

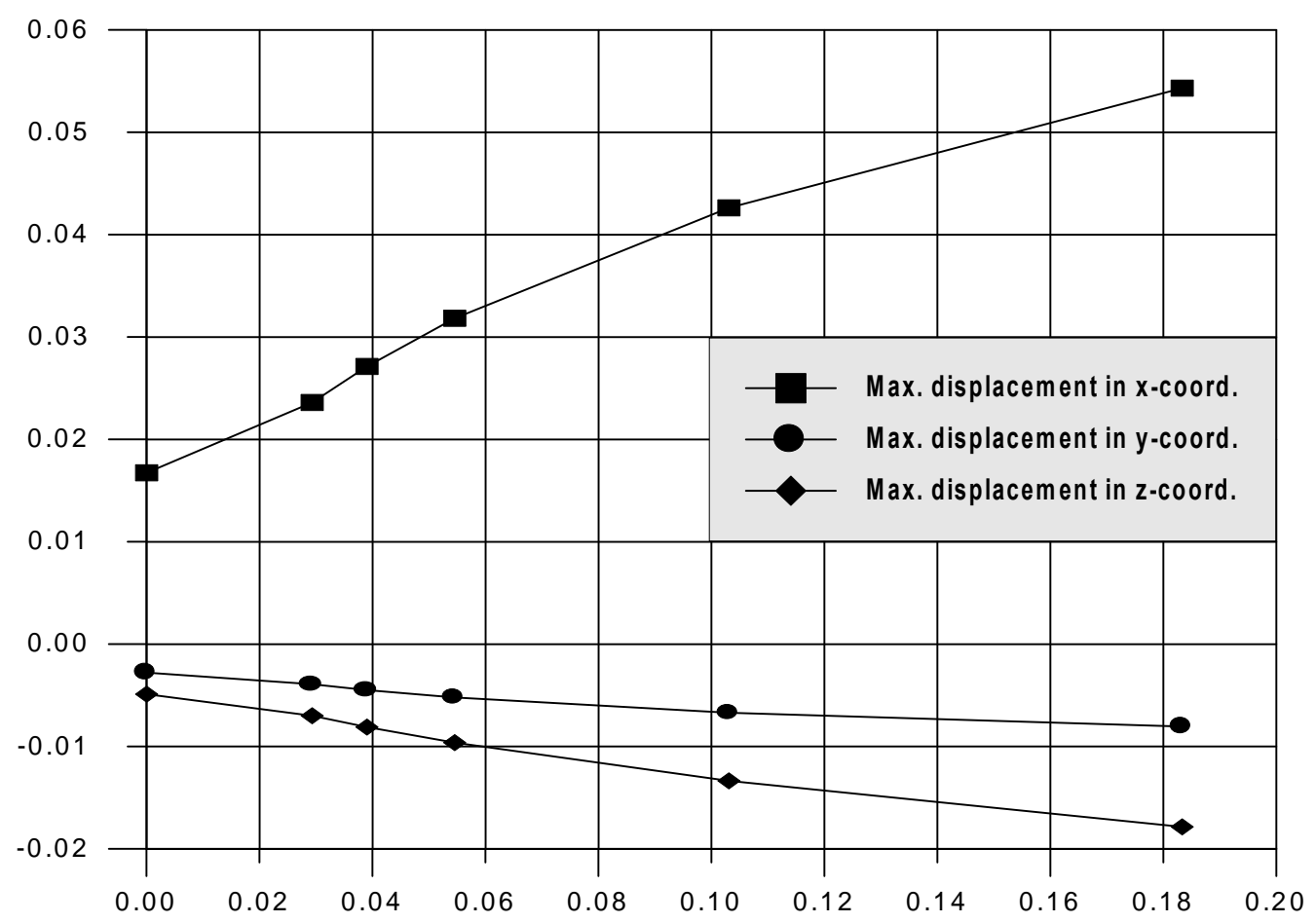

(15): تز ايد أكبر قيم متولدة للإزاحات باتجاه الإحداثيات الثلاثة 


\section{6. الاستنتاجات:}

بعد إجر اء هذه الدر اسة ومناقثـة النتائج المستحصلة منها، يمكن الخروج بالاستنتاجات

$$
\text { ـ فعاليـة البرنـامج الذي تـم تطـوبره في دراسـة تغير تـوزع الإجهادات مـع تغيـر زاويـة }
$$

ـ تغير توزع الإجهادات المتولدة في السن وتز ايد قيمها مـع تغير زاويـة عدم المحاذاة. إذ بزداد

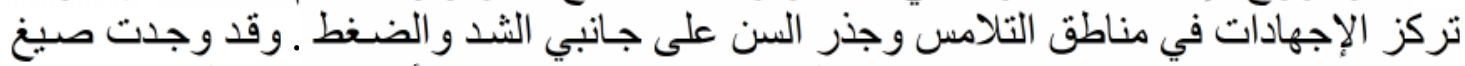

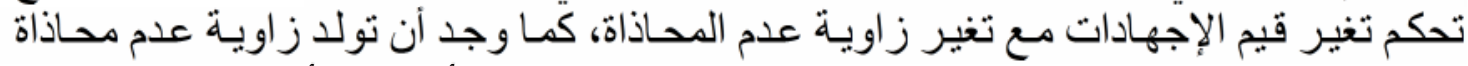
(0.1degree)

\% 163 في قيمة إجهاد القص الأعلى و 1 \% 147 في قيمة الإجهاد الأسأسي الأدنى في منطقة

• ازدياد اكبر قيم للإز احات المتولدة باتجاه الإحداثيات الثثلاثة مـع ازديـاد زاويـة عدم المحساذاة، مما يدل على ازدياد تشوه السن.

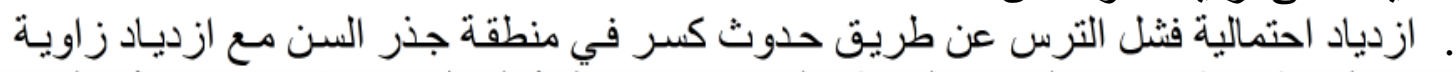

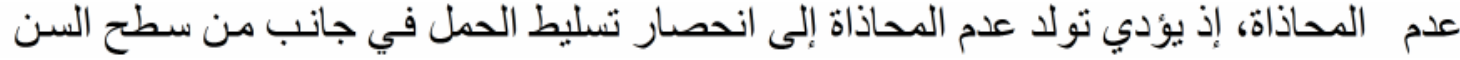

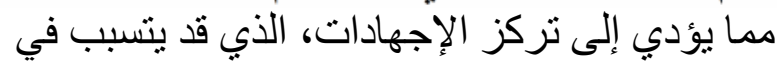

\section{7. التوصيات:}

يمكن تقديم التوصيات الآتية لغرض تقليل احتمالية فثل السن:

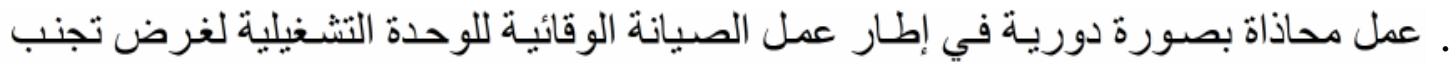

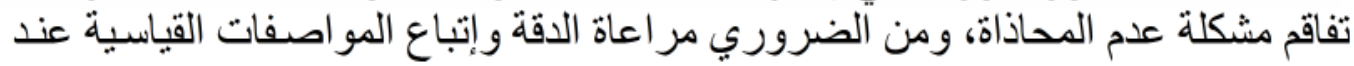

ـ إبدال السبيكة المعدنية المستخدمة في صناعة الترس بسبيكة أخرى، ذات إجهاد خضوع ألمان أعلى،

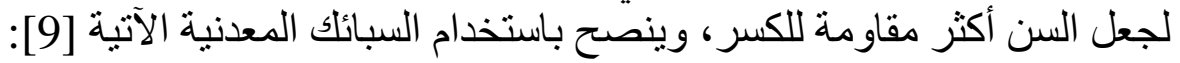




\begin{tabular}{|c|c|c|}
\hline \multicolumn{2}{|c|}{ Alloy designation } & Yield stress \\
DIN & AISI $\left.\mathbf{m m}^{\mathbf{2}}\right)$ \\
\hline 1.5919 & 3115 & 635 \\
$15 \mathrm{CrNi} 6$ & 4135 & 665 \\
\hline 1.7220 & & \\
$34 \mathrm{CrMo} 4$ & 3415 & 735 \\
\hline 1.5752 & & 765 \\
$14 \mathrm{NiCr} 14$ & 4140 & \\
\hline 1.7225 & & 785 \\
$42 \mathrm{CrMo} 4$ & 6150 & \\
\hline 1.8159 & & \\
\hline $50 \mathrm{CrV} 4$ & & \\
\hline
\end{tabular}

(4): السبائك المعدنية التي ينصح باستخدامها في صناعة الترس 
1. Wilcox L., and Coleman W., "Application of Finite Element to the Analysis of Gear Tooth Stresses ", Journal of Engineering for Industry, Vol. 95, No. 4, pp. $1139-1148,1973$.

2. Chabert G., Dang Tran T., and Mathis R., "An Evaluation of Stresses and Deflection of Spur Gear Teeth Under Strain", Journal of Engineering for Industry, Vol. 96, No. 1, pp. 85 - 93, 1974.

3. Sayama T., Oda S., and Umeezawa K., " Root Stresses and Bending Fatigue Strength of Welded Structure Gears ", International Symposium on Gearing \& Power Transmissions, Japan, Tokyo, 1981.

4. Ristivojevic M., "Development of the Theoretical Model for Determining the Stress Authoritative for Checking the Gear Tooth Volume Strength", Mechanical Engineering Series, Vol. 1, No. 9, pp. 1135-1145, 2002.

5. Smith I.M., and Griffithis D.V., "Programming the Finite Element Method", John Wiley \& Sons, Inc., U.S.A, New York, 1998.

6. Pandya N.C., and Shah C.S., "Elements of Machine Design", Charotar Publishing House, India, 1986.

7. Niemann G., "Machine Elements", Allied Publishers Private, Ltd., India, New Delhi, 1980.

8. Maitra G.M., “ Handbook of Gear Design ”, Tata McGraw-Hill Company, India, NewDelhi, 1997.

9. Steel Manual, Vereinigte Edelstahl Werke (VEW), Austria, Vienna, 1986. 